
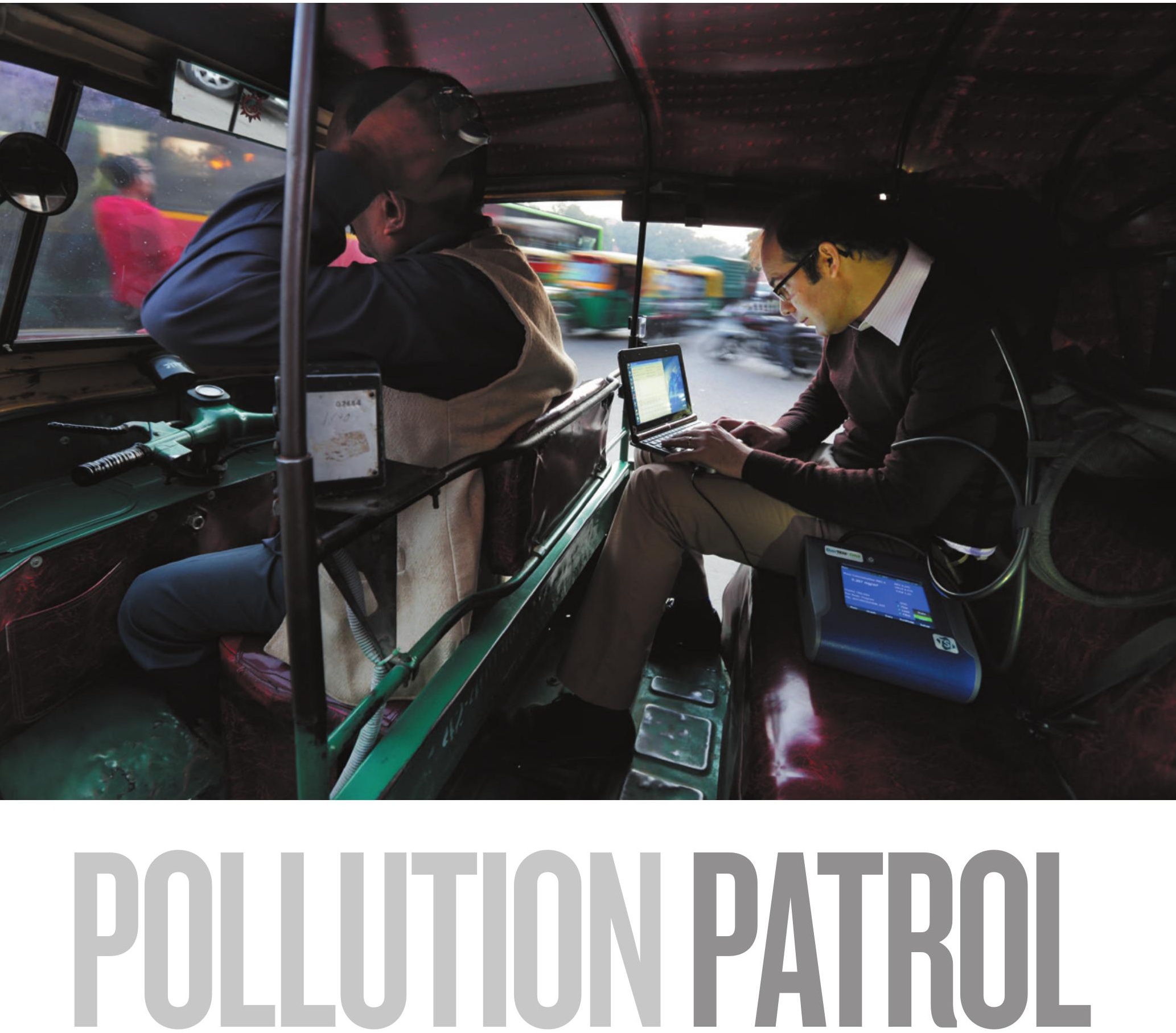

Step aside, fitness trackers. The next wave of personal sensors is giving people the ability to monitor the air they breathe.

\section{BY KAT AUSTEN}

W hen winter descends on Ulaanbaatar, Mongolia, the air turns foul. Here in the world's coldest capital city, residents light open fires of coal or wood to heat their uninsulated houses. Soot fills the skies, and people don face masks to ward off smog so thick it can hide buildings a few hundred metres away. "White clothing becomes grey after a few hours," says Munkhmandakh Myagmar, executive director of the Press Institute of Mongolia.

The city is one of the most polluted in the world, according to the World Health Organization (WHO) - and estimates suggest that particulate air pollution causes one-tenth of the city's deaths. But information about the extent of that pollution is limited and hard to find. The WHO's online database for pollution has readings from just one year for Ulaanbaatar, 
Joshua Apte travels around New Delhi in an auto rickshaw to measure air-pollution levels on the city's busy roads. showing concentrations of harmful particles called $\mathrm{PM}_{10}$, which have a diameter of 10 micrometres or less, and $\mathrm{PM}_{2.5}$, with a diameter of 2.5 micrometres or less.

Eager to fill the knowledge gap, journalists from the Press Institute are taking matters into their own hands. In collaboration with the Earth Journalism Network - an international group of environmental journalists - Myagmar and her colleagues distributed five devices, each about the size of a child's lunch box, around the city in July.

Called DustDuinos, the devices measure particulatematter concentrations and quickly upload the data to a public website. Despite some initial problems with charging and connectivity, preliminary results from a sensor in the city's centre showed that concentrations of $\mathrm{PM}_{10}$ often surged to at least twice the WHO's recommended limit.

The DustDuino and other pollution sensors, some of which can be built for as little as US\$50, and instructions for which are available online, are part of the next wave in the environmental movement (see 'Sensors for the people'). Across the globe, journalists, advocacy groups, hackers and others are starting to use low-cost monitoring devices to vastly expand the amount of data that are publicly available on forms of air pollution such as particulate matter and toxic gases. The devices are easy to deploy and can complement data from official networks, which rely on sophisticated but sparsely distributed sensors. The 'citizen-science' approach aims to provide high-resolution measurements of air pollution where people actually live. Work is also under way to develop wearable sensors to monitor personal exposure levels.

Built on the principle of openness, such do-it-yourself (DIY) efforts are part of a push to democratize air-quality monitoring so that it no longer remains solely in the domain of governments and academic researchers. But advocates of the approach still have to convince conventional pollution researchers, who worry about the quality and usability of data from cheap sensors operated by relatively untrained people.

Still, everyone agrees that more resources need to go into monitoring air pollution, which kills around 7 million people a year. "It's the largest, single most important, environmental health risk in the world," says Joshua Apte, an environmental researcher at the University of Texas at Austin, who sees an emerging role for cheap, plentiful pollution gauges. "The fact that you can buy 50 low-cost sensors for the cost of one regulatory sensor is a tremendously powerful thing."

\section{POLLUTION PIGEONS}

The roots of the movement go back to 2006, when Beatriz da Costa, an artist at the University of California, Irvine, strapped a small bundle of sensors onto homing pigeons. Da Costa had worked with engineers to develop the instrument package, which measured carbon monoxide and nitrogen oxides and tracked the pigeons' movements using a Global Positioning System (GPS) receiver. She published the data from her project, called PigeonBlog, with the aim of disrupting the status quo and giving the public a role in gathering data on pollution.

Around the same time, sensors for other uses were starting to emerge. More than two-thirds of US adults now say they use technology to track their heart rate and other health data; gadgets for the home sense water and electricity usage by the minute, and cities are employing sensors to track everything from pedestrian traffic to leaky pipes.

Options for grass-roots pollution monitoring were scarce until a few years ago: conventional air-quality sensors are expensive or require training, and the data they provide are often inaccessible or hard to work with and share. That began to change when 'makers' - tinkerers who work in backyard sheds and collective hackspaces - started soldering together circuit boards and sensors to take on the challenge.

In 2011, a group of hackers, makers and artists who called themselves the Sensemakers gathered at meet-ups in Amsterdam and New York. Governments were not monitoring pollution at the local level, where it affects people, they wrote on their blog. The Sensemakers launched an online call for a community-developed sensor that would measure air pollution. With more than $\$ 144,000$ raised through the crowdfunding platform Kickstarter, the Sensemakers developed the Air Quality Egg, a device to measure temperature, humidity, carbon dioxide and nitrogen dioxide. The sensor costs $\$ 185$ - less than one-tenth the price of a mid-range device.

Similar efforts were emerging in Spain at around the same time. Tomas Díez Ladera, director of Fab Lab Barcelona at the Institute for Advanced Architecture of Catalonia, had dreams of citizens being able to monitor the air they breathe

\section{"IT'S THE LARGEST, SINGLE MOST IMPORTANT, ENVIRONMENTAL HEALTH RISK IN THE WORLD."}

in real time and stream the data so that others in their community could benefit. After spending a year looking at what technology was available, Díez Ladera decided that he and his team would have to realize this dream themselves. Their early prototypes grew into a package of sensors called the Smart Citizen Kit (SCK) - which measures everything the Air Quality Egg does, as well as light intensity and noise. The group launched a website to encourage DIY-ers to build or buy the device and monitor local pollution.

Because open-source sensors such as these can be made anywhere, it is difficult to track how many have been produced. But according to their inventors, at least 35 DustDuinos, some 2,500 Air Quality Eggs and 1,000 SCKs have been deployed. Many of the data produced by these devices are openly available through online platforms such as Xively.

These efforts have already captured the attention of city officials and citizen groups. In early 2014, officials in Amsterdam provided 100 citizens with SCKs and instructions on how to use them in their neighbourhoods. In May, a community effort coordinated by FutureEverything, an innovation lab in Manchester, UK, created a network of sensors around that city's centre. The aim is to test how such data can enhance urban living by showing, for example, how efforts to encourage bicycling affect air quality.

\section{DATA DIVIDE}

All this enthusiasm by proponents has not yet won over environmental researchers. The sensors currently used in the SCK and the Air Quality Egg are not up to the task of providing robust pollution data, says Ben Barratt, an air-quality scientist at King's College London, who helps to run the London Air Quality Network, an online resource for pollution data.

"Monitoring air-pollution levels is far more involved than the manufacturers and suppliers of cheap sensors suggest," Barratt says. The problem is that temperature, humidity and some gases skew the results from sensors such as those used in the Air Quality Egg and SCK, making 


\section{SENSORS FOR THE PEOPLE}

How polluted is your home or neighbourhood? Until recently, it was difficult to answer that question because data were available only from networks of expensive sensors in relatively limited locations. The do-it-yourself movement has led to the emergence of low-cost sensors that can be purchased or built from online instructions.

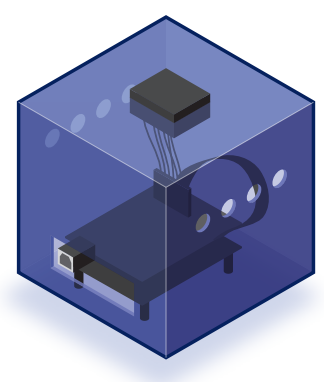

DUSTDUINO

Measures the concentration of pollution particles equal to or smaller than 10 micrometres $\left(\mathrm{PM}_{10}\right)$ and 2.5 micrometres $\left(\mathrm{PM}_{2.5}\right)$.

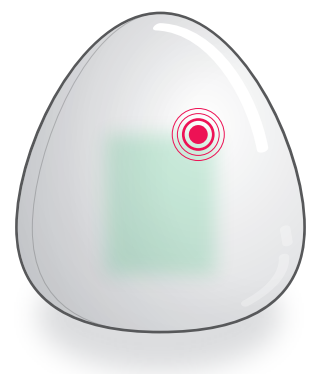

\section{AIR QUALITY EGG}

Measures nitrogen dioxide and carbon monoxide, humidity and temperature. Streams data online through a separate base station.

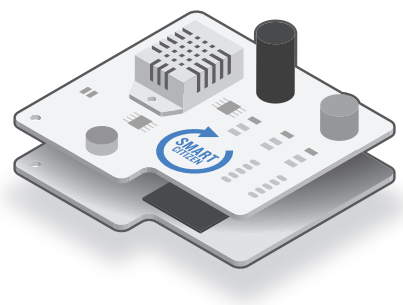

SMART CITIZEN KIT

Measures nitrogen dioxide and carbon monoxide, as well as light, humidity, temperature and noise pollution. it difficult to compare results between devices, he says.

DIY endeavours also lack input from pollution experts, says Tim Chatterton, a pollution-policy researcher at the University of the West of England in Bristol, UK, who has worked with the UK government to monitor air quality. Professional technicians and scientists pay close attention to siting and maintaining sensors, he says. "Without due attention to these things, the data is essentially meaningless because it's not comparable."

These problems reduce the usefulness of such data in environmental advocacy, says Kirk Smith, an environmental health researcher at the University of California, Berkeley. The US Environmental Protection Agency (EPA) has strict rules about what holds up in court, he says, "and these monitors don't meet their criteria - yet".

The data are also often streamed and stored in ways that make them difficult to analyse and visualize to tell a coherent

\section{"THIS NEW TECH IS POTENTIALLY VERY VALUABLE. AND IT'S COMING, WHETHER OR NOT WE ARE INVESTING OR USING IT."}

story, adds Smith, whose group has created particulate-matter sensors for use indoors. "One thing we learned in developing our smart, cheap monitors is that they are producing a lot of data and it's not clean. To get something useful out of the end takes a lot of work," he says.

Given such concerns, the keepers of scientific data sets have not yet embraced the information produced by most DIY sensors. Barratt, for example, says he will not include data from citizen-sensing projects in the London Air Quality Network until the quality improves.

Matthew Schroyer, who developed the DustDuino, says that its data are comparable to those generated by more expensive sensors when averaged over a sufficient time span. An independent team of researchers reported that the sensor used in the DustDuino performs as well as a higher-cost sensor when sampling air quality over windows of 1 hour (D. M. Holstius et al. Atmos. Meas. Tech. Discuss. 7, 605-632, 2014). Schroyer, a technology developer and communications specialist in Champaign, Illinois, acknowledges that the DustDuino is not accurate enough for instantaneous data gathering, because its measurements contain too much noise.

The developers of the Air Quality Egg and the SCK also recognize that the sensors face teething problems, but they say that they are addressing them. Díez Ladera says that the next release of the SCK, expected in early 2015, will be precalibrated and have better sensors, which should make its data reliable enough for comparison with official air-quality standards.

Apte's previous work has shown just how important it is to understand how pollution levels vary at the human scale. Last year he spent four months driving through New Delhi's frenetic roads on a rickshaw kitted out with a mid-range sensor called a DustTrak, which can deliver real-time feedback about pollution.

Apte wanted to understand how pollution levels change as people go about their daily business - and he discovered large variations. In traffic, for example, a passing truck spewing smoke can cause concentrations of $\mathrm{PM}_{2.5}$ to jump by as much as $50 \%$.

During those rides, Apte found even greater fluctuation in the levels of harmful ultrafine particles, which are smaller than $\mathrm{PM}_{2.5}$, and of pure carbon specks. "We're interested in deploying networks of air-pollution monitors all around cities," says Apte. "You couldn't do this if you were paying $\$ 10,000$ per sensor."

Other researchers are engaging with the citizen-sensing movement. Despite his concerns over the data quality, Barratt is advising projects such as the London Sustainability Exchange, which is working with communities to measure air pollution in the city.

The EPA is also starting to embrace the citizen-monitoring concept. Tim Watkins, acting deputy director of the EPA's National Exposure Research Laboratory, wants to explore how cheaper, less accurate sensors can provide data that will complement the sparsely spaced, top-of-the-range kits. "This new tech is potentially very valuable. And it's coming, whether or not we are investing or using it," he says.

In 2013 the EPA announced the winners of a competition for developers to create low-cost wearable sensors that integrate air-quality measurements with health data. And in the next few months the agency will announce the winners of a $\$ 4.5$-million competition to fund research on community use of low-cost sensors to measure air quality.

As budget cuts cause governments to trim expensive sensor networks, citizen sensing will develop to fill the gap, says Schroyer. He foresees a day when people's clothes will measure their exposure to carcinogens, their phones will sniff for polluting particles and drones will hover over cities, searching for natural-gas leaks. "Mobile, fabrics, health monitors - these are all quite possible," he says. "There are hackers the world over working on these technologies right now."

Kat Austen is a freelance writer in Berlin. 